\title{
A03 Use of DST for Effective Dynamic Appraisal: Case Studies from Deep Offshore West Africa and Associated Methodology
}

Jean-Luc Boutaud-de-la-Combe, Total

In the emerging West Africa deep offshore region, where exploration is booming, the turbiditic series reservoirs are mostly structurally trapped with a stratigraphic component. Faulting is severe inducing high compartmentalisation. Evaluation of connectivity and characterisation of the reservoir heterogeneities before development decisions are the main challenges.

This long DST acquired at a relatively early stage of the appraisal was a game changer for the development project. It demonstrated large scale reservoir continuity in a complex geological setting, which in turn provided extra-confidence on the feasibility of a large scale development project. The confrontation of this wide scale dynamic information to seismic data and geological concepts allowed significant optimisation of the remaining appraisal sequence.

Testing methodology, based on Total experience, advocates the setting of two cycles of draw-down and build-up to generate significant depletion between the two build-up's. This test sequence allows discriminating between geological models matching the derivative and assesses a minimum hydrocarbon connected volume.

This case study concerns an appraisal well drilled in 2003 to recognise the turbiditic series of Late Miocene age in the Southern panel of a structure discovered in 2002. This test allowed us to prove a minimum oil connected volume of at least $120 \mathrm{MMbbls}$, much larger than the pre-test volume of $55 \mathrm{MMbbls}$ estimated from seismic interpretation, and proved an extension of good reservoir facies beyond the seismic visibility limit. 